\title{
Recruitment into psychiatry: quantitative myths and qualitative challenges ${ }^{\dagger}$
}

Teifion Davies

\section{Summary}

Recruitment into psychiatry is perceived as problematic in the UK but the paper by Goldacre and colleagues in this issue of the Journal shows that recruitment of new UK graduates has altered little over 35 years.

Sources of psychiatry's malaise should be sought in its changing focus and the quality, rather than quantity, of its recruits

Declaration of interest

None.
Teifion Davies is senior lecturer in psychiatry at King's College London Institute of Psychiatry, and Specialist Advisor on CASC Development at the Royal College of Psychiatrists.

Psychiatry is a major medical specialty in the UK, accounting for over $10 \%$ of all doctors in secondary care in England, and about $11.5 \%$ of consultant posts. ${ }^{1}$ Indeed, if the prowess of a medical specialty can be judged from its size, then over the past decade UK psychiatry has gone from strength to strength. From 2000 to 2011, the absolute number of consultant psychiatrists in England rose from 2904 to 4394 (an increase of 51\%), with similar increases in Scotland and Wales, in line with the expansion of the consultant workforce in most secondary care specialties. ${ }^{1}$ The majority of the increase $(87 \%)$ was accounted for by female staff. A need for more psychiatric consultant posts in the period up to 2014 has been predicted based on projections of increasing clinical and medico-legal workload. ${ }^{2}$ Despite this, the spectre of falling recruitment has haunted UK psychiatry in recent years. ${ }^{3,4}$ A perceived fall in the proportion of UK medical school graduates choosing a postgraduate career in psychiatry, and low competition ratios for first-year core specialist training (CT1) posts in psychiatry, ${ }^{5-7}$ have generated much soul-searching about what is taught in medical schools, and how psychiatry could be made to appear more attractive. ${ }^{8-10}$

The study by Goldacre and colleagues ${ }^{11}$ from the UK Medical Careers Research Group in this issue of the Journal exorcises some of these ghosts, and raises some interesting new visions of the future of psychiatric recruitment in the UK. The researchers ascertained career choices using an established questionnaire methodology that was applied to all medical graduates of all UK medical schools in each of 12 cohorts of graduates between 1974 and 2009. In three cohorts $(2002,2005,2009)$, questions were added about careers that had been 'seriously considered' but rejected, and the reasons for the rejection. Two important findings challenge established, and deeply ingrained, views about quantitative aspects of recruitment into psychiatry. First, the proportion of graduates in UK medical schools specifying psychiatry as their intended career destination has varied little over the 35 years during which these career surveys have been conducted. That proportion, although low, has remained relatively stable between 4 and $5 \%$; this is comparable with other high-income countries (such as the USA ${ }^{12}$ ), and is capable of

†See pp. 228-234, this issue. maintaining a more than ten-fold difference between the number of psychiatrists per head of population in high-income countries and low- and middle-income countries. ${ }^{13,14}$ Second, although the proportion of male graduates entering psychiatry has been consistent for about 25 years, the proportion of women doctors choosing psychiatry has begun to decline. As the authors suggest, the latter finding might result from psychiatry losing its relative 'family friendly' appeal as other (acute medical and surgical) specialties benefit from improved flexible training schemes ${ }^{15}$ and the European Working Time Directive.

Where, then, are we to look for an explanation of the apparent numerical deficiencies in psychiatric recruitment? First, at the population base from which future psychiatrists are recruited: according to the Organisation for Economic Cooperation and Development (OECD), the number of medical graduates in the UK rose from 4432 in 2000, peaking at 6208 in 2007, and stabilising at 5757 in $2010 .{ }^{16}$ This $30 \%$ increase was outstripped in the same decade by the $>50 \%$ increase in medical staff overall (general practice plus hospital specialties). ${ }^{1}$ Thus, at an estimated $5 \%$ rate of recruitment, the yield of new doctors from all UK medical schools wishing to enter psychiatry is only about twothirds of the number required to fill all CT1 vacancies in England. ${ }^{7}$ Even allowing for the increase in UK medical school intake over the same period (to about 6400 by 2010 but reducing by $2 \%$ from 2013), ${ }^{17}$ and assuming all students graduate after a lag period of 5-7 years, applying the same estimated recruitment rate predicts only $90 \%$ of posts would be filled. Second, it is probable that failure to fill all psychiatry training posts is not a new phenomenon. Centralised recruitment to a national scheme, rather than by individual trusts or training schemes, has shown up deficiencies that were likely to have been present in the past but were overlooked because popular schemes at major 'centres of excellence' were not affected. Third, this shortfall might have been met partially in the past by international (European Union (EU) and non-EU) medical graduates (IMGs). ${ }^{13}$ However, recent changes in UK immigration and visa requirements have limited severely the numbers of non-EU IMGs available for this role, and the number of EU graduates seeking employment in the UK is too small, except in some specialist areas, to make up the deficit. ${ }^{1}$ Whatever the cause of low recruitment rates into psychiatry, uptake from UK medical schools would need to increase to an average of at least $8 \%$ if competition ratios for CT1 posts are to be kept above one. The Royal College of Psychiatrists has squared up to this task but the lead time on implementation of the recruitment strategy, ${ }^{10}$ even if maximally successful, is likely to be 5 or 6 years during which clinical psychiatry will suffer continued attrition. 


\section{Quality matters more than numbers}

Discerning the true picture of recruitment from these disparate and partial data is fraught, and any conclusion is unlikely to appeal to all those with a vested interest. What is clear is that a simple quantitative view of recruitment is unhelpful, and what is much more important is the impact that low recruitment rates, resulting in competition ratios near to or below one, will have on the quality of entrants to the specialty. Several reasons for this may be outlined. First, data from the present study and from the deanery CT1 recruitment process, ${ }^{6,7}$ suggest that psychiatry is already a popular second, third or even fourth choice for new doctors. On the one hand, this halo phenomenon indicates a group that might be identified early and targeted to raise their interest in psychiatry. On the other, due to the gaming nature of the CT1 application process, more able candidates who place psychiatry lower in their preferences are likely to gain their first (non-psychiatry) choice, leaving the field for less able candidates who fail to gain their first choice. Second, if, as suggested by this study, female candidates are ceasing to see that psychiatry can be both a rewarding and family friendly career choice, then the loss to psychiatry will be more than mere numbers. This is because female candidates regularly out-perform their male counterparts in both MRCPsych written and clinical examinations regardless of their ethnic origin or location of primary medical qualification. ${ }^{18}$ Women doctors have become the intellectual core of British psychiatry and to lose them to men who might be, on average, less able would be debilitating to the specialty in the longer term. If women doctors are beginning to regard acute medical and surgical specialties as being as appealing as psychiatry, then we should heed the warning: better working conditions in other specialities have levelled the playing field.

\section{Simple questions, difficult answers}

Should the current size (and proposed future expansion) ${ }^{2}$ of the specialty be maintained? In effect, is psychiatry 'too big to fail'? Goldacre et $a l^{11,19}$ have shown that in the UK psychiatry is not less popular with new doctors seeking a specialist career: it has, however, expanded beyond the supply of new recruits. If the quality of recruits is to be maintained or, indeed, improved, then the status quo could continue only at the cost of vacant posts in the training grades and ultimately at consultant level, creating a sort of psychiatric 'stagflation'. To achieve the alternative of filling all training grade posts in order to ensure a pipeline of succession to consultant grade must entail opening the specialty to less able applicants - making psychiatry something of an easy career option.

As a medical specialty that has psychosocial, as well as biomedical, principles at its core, psychiatry has been in the vanguard of the integration of health and social care. It has expanded into areas ever further from the core remit of the psychiatrist with, for instance, some community mental health services becoming increasingly responsible for delivering social rather than biopsychosocial care (causing some to question the future of the specialty). ${ }^{20}$ Doctors are relatively expensive employees, and already expansion has brought the specialty into direct competition with a variety of commercial, not-for-profit and 'third sector' organisations that are viewed by the commissioning authorities as capable of delivering, for example, addiction, forensic rehabilitation and community services more cost-effectively than the conventional national health service (NHS) provision. Psychiatry finds itself squeezed between a lack of supply (of suitable recruits) at the bottom and a lack of demand (from commissioners) at the top. In such circumstances, the imperative to increase recruitment numbers will be perceived as an attempt to maintain a diffuse, jack-of-all-trades special interest group rather than specialty. Of the many possible courses of action the most appealing is an emphasis on core values and purpose, by raising (rather than lowering) the entry threshold to a necessarily smaller number of core training posts, and presenting to service commissioners a workforce that is tightly defined by its biomedical training as capable of delivering what no one else can, the biomedical component of specialist mental healthcare.

Finally, what should psychiatry ask of undergraduate medical education? The answer is the same as for any other specialty: to produce high-quality, omnicompetent medical graduates capable of practising under supervision, of entering any specialty and of meeting the basic medical needs of patients in any setting. ${ }^{21}$ It would be invidious if each specialty biased its undergraduate course towards postgraduate recruitment, by showing only its attractive elements while denigrating other specialisms. This is not to suggest that undergraduate psychiatry is unimportant; on the contrary, it is crucial to the development of all doctors and, in the present context, to the future of psychiatry as a medical specialty.

Teifion Davies, PhD, CBiol, MSB, FRCPsych, Division of Psychological Medicine (PO63), King's College London Institute of Psychiatry, De Crespigny Park, London SE5 8AF, UK. Email: teifion.davies@kcl.ac.uk

First received 19 Nov 2012, final revision 4 Dec 2012, accepted 16 Jan 2012

\section{References}

1 HM Government. NHS Staff (Medical and Dental). Data.Gov.UK, 2012 (http://data.gov.uk/dataset/nhs-staff-2000-2010-medical-and-dental).

2 Centre for Workforce Intelligence. Shape of the Medical Workforce: Informing Medical Training Numbers. Centre for Workforce Intelligence, 2011 (http:// www.cfwi.org.uk/publications/medical-shape-2011).

3 Brockington IF, Mumford DB. Recruitment into psychiatry. Br J Psychiatry 2002; 180: 307-12.

4 Brown N, Vassilas CA, Oakley C. Recruiting psychiatrists - a Sisyphean task? Psychiatrist 2009; 33: 390-2.

5 Royal College of Psychiatrists. Census 2009: Workforce Figures for Psychiatrists. Royal College of Psychiatrists, 2010 (http://www.rcpsych.ac.uk/ pdf/2009\%20Census.pdf).

6 Carr A, Sullivan E, Buggle S, Hamilton P. Specialty Training at ST1 and CT1 in England. BMJ Careers, 2011 (http://careers.bmj.com/careers/advice/ view-article. html id = 20005662)

7 Royal College of Psychiatrists. Fill Rate and Competition Ratios for CT1 August 2012 Intake. Royal College of Psychiatrists, 2012 (http:// www.rcpsych.ac.uk/pdf/CT1\%20fill\%20rate-10.09.2012.pdf).

8 Brown T, Eagles J. Teaching Psychiatry to Undergraduates. RCPsych Publications, 2011

9 Gask L, Coskun B, Baron D. Teaching Psychiatry: Putting Theory into Practice. Wiley, 2011.

10 Royal College of Psychiatrists. Recruitment Strategy 2011-2016. Royal College of Psychiatrists, 2012.

11 Goldacre MJ, Fazel S, Smith F, Lambert T. Choice and rejection of psychiatry as a career: surveys of UK medical graduates from 1974 to 2009. Br J Psychiatry 2013; 202: 228-34.

12 American Psychiatric Association. Resident Census. Characteristics and Distribution of Psychiatry Residents in the US 2010-2011. APA, 2011.

13 Höschl C, van Niekerk J. Recruitment of psychiatrists: the key role of education. In Teaching Psychiatry: Putting Theory into Practice (eds L Gask, B Coskun, D Baron): 5-18. Wiley, 2011.

14 Organisation for Economic Cooperation and Development. Health at a Glance 2011: OECD Indicators. Healthcare Workforce: Psychiatrists. OECD, 2011 (http://www.oecd-ilibrary.org/sites/health_glance-2011-en/03/06/index.html? contentType $=/ \mathrm{ns} /$ Chapter $/$ /ns/StatisticalPublication\&itemld $=/$ content/chapter/health_glance-2011-25-en\&containerltemld = /content/ serial/19991312\&accessltemlds = \&mimeType $=$ text/html). 
15 NHS Employers. Doctors in Flexible Training. Principles Underpinning the New Arrangements for Flexible Training. NHS Employers, 2005. (http:// www.nhsemployers.org/SiteCollectionDocuments/doctorstraining_flexible_ principles_cd_080405.pdf).

16 Organisation for Economic Cooperation and Development. Health at a Glance 2011: OECD Indicators. Healthcare Workforce: Medical Graduates. OECD, 2011 (http://www.oecd-ilibrary.org/sites/health_glance-2011-en/03/03/ index.html? contentType $=/ \mathrm{ns} /$ Chapter,$/ \mathrm{ns} /$ StatisticalPublication\&itemld $=/$ content/chapter/health_glance-2011-22-en\&containerltemld =/content/serial/ 19991312\&accessltemlds = \&mimeType = text/html).

17 Health and Education National Strategic Exchange. Review of Medical and Dental School Intake in England. HEFCE \& Department of Health, 2012 (http://www.dh.gov.uk/health/2012/12/medical-school-intakes/).
18 Royal College of Psychiatrists. MRCPsych Examinations Cumulative Results 2008-2010. Royal College of Psychiatrists, 2011 (http:// www.rcpsych.ac.uk/pdf/MRCPsych\%20Cumulative\%20Results\%20Report \%20-\%20August\%202011.pdf).

19 Goldacre MJ, Goldacre R, Lambert TW. Doctors who considered but did not pursue specific clinical specialties as careers: questionnaire surveys. J R Soc Med 2012; 105: 166-76.

20 Craddock N, Antebi D, Attenburrow M-J, Bailey A, Carson A, Cowen P, et al. Wake-up call for British psychiatry. Br J Psychiatry 2008; 193: 6-9.

21 Davies T. Integration: teaching psychiatry with other specialties. In Teaching Psychiatry to Undergraduates (eds T Brown, J Eagles): 186-204. RCPsych Publications, 2011

\section{poem}

\section{The First Shift}

\section{Victoria Cole}

Hoisted out, you remain Buddha-like,

betraying the fact

that I am the one supposed to convey inner calm.

Threaded puppet legs dangle.

I remove the piss-stained sheets

with a soliloquy about the state of the English weather

and last night's football match.

Your response is a rattle.

I feed you scrambled egg from a small plastic spoon

I cluck and encourage like a mother hen.

You open your beak and gape.

I scrape the plate clean and pop it all in.

Before the crisp white sheet makes its full descent,

it is tamed and tucked,

take pride in my hospital corners.

My hands work deftly

To smooth away the creases.

It is only then

I notice you watching me.

Victoria Cole originally trained as a mental health nurse. Currently, she is the clinical team leader for a psychological therapy service in North Devon, UK.

This poem is from The Hippocrates Prize 2011, published by The Hippocrates Prize in association with Top Edge Press (c) Victoria Cole.

Chosen by Femi Oyebode. 